\title{
Development of Tetra-primer Amplification Refractory Mutation System (ARMS) PCR for Detection of CHRNA3 rs8040868
}

\author{
Anggi Laksmita Dewi ${ }^{1}$, Dewi Kartikawati Paramita ${ }^{2}$, Jajah Fachiroh ${ }^{2, *}$ \\ ${ }^{1}$ Magister Program of Biomedical Sciences, Faculty of Medicine, Public Health and Nursing, Universitas Gadjah Mada, Jl. Farmako, Sekip Utara, \\ Yogyakarta 55281, Indonesia \\ ${ }^{2}$ Department of Histology and Cell Biology, Faculty of Medicine, Public Health and Nursing, Universitas Gadjah Mada, Jl. Farmako, Sekip Utara, \\ Yogyakarta 55281, Indonesia \\ *Corresponding author. E-mail: jajahfachiroh@ugm.ac.id
}

Received date: Nov 23, 2020; Revised date: Apr 19, 2021; Accepted date: Apr 21, 2021

\section{Abstract}

B ACKGROUND: Single nucleotide variations (SNV) have been mapped to be associated with several human conditions and diseases. To validate the association between SNV to certain human traits or diseases, a large number of subjects must be included. Thus, in need of a fast, relatively economic, and reliable genotyping method. This can be achieved through the use of tetra-primer amplification refractory mutation system polymerase chain reaction (Tetra-primer ARMS PCR). This study reports strategy to develop Tetra-primer ARMS PCRbased genotyping of CHRNA3 rs8040868.

METHODS: The optimization of Tetra-primer ARMS PCR was done through these steps: identification of gene sequence and position of single mutation; designing outer and inner PCR primers; amplification of target gene fragments through PCR by using outer primer; confirming genotype of the
PCR product by using sequencing; determining an optimum ratio of outer and inner primer; and determining optimum annealing temperature and cycles for the PCR program. The PCR products were run in $2 \%$ gel agarose electrophoresis and visualized under UV illumination.

RESULTS: Outer and inner primer ratio of 1:3 with annealing temperature of $64.4^{\circ} \mathrm{C}$ and $40 \mathrm{x}$ cycles was found to be the most optimum condition. Tetra-primer ARMS PCR was able to confirm the results of the DNA sequence of 2 samples, confirming wild-type variants (TT allele) and the heterozygous mutant (CT allele).

CONCLUSION: Tetra-primer ARMS PCR was able to genotype rs8040868 of the CHRNA3 gene.

KEYWORDS: tetra-primer ARMS PCR, CHRNA3, rs8040868, genotyping

Indones Biomed J. 2021; 13(2): 192-200

\section{Introduction}

Single nucleotide variation (SNV) is a variation in the DNA sequence that occurs when one base is substituted with another base, undergoes insertion (addition), or deletion (reduction). SNV is the simplest form of polymorphism in the human genome that can occur in the coding and noncoding sections. SNV is estimated to occur per 500-1000 base pairs in a genome and affect more than $1 \%$ of the population. $(1,2)$
The variation of CHRNA3 rs 8040868 is one of the known SNV in chromosome 15. This synonymous mutation (Valine) changes the allele from Thymine (T) to Cytosine (C) in region Exon 2. Detailed characteristics of this variant taken from the National Center for Biotechnology Information (NCBI) database can be found in Table 1.

Located in the $15 \mathrm{q} 25.1$ locus, the CHRNA3CHRNA5-CHRNB4 gene cluster is known to be associated with smoking-associated cancer.(3) Genetic variation of CHRNA3 rs8040868 is considered as a pathogenic mutation associated with a phenotype of non-small cell lung cancer 
Table 1. CHRNA3 rs8040868 variant information.

\begin{tabular}{cccccc}
\hline Gene Variant & Position & Region & Changes & Allele & Effect \\
\hline $\begin{array}{c}C H R N A 3 \\
\text { rs8040868 }\end{array}$ & $\operatorname{chr} 15: 78.618 .839$ & Exon 2 & $\begin{array}{c}\text { c.159 } \\
\mathrm{A}>\mathrm{G}\end{array}$ & $\mathrm{T} / \mathrm{C}$ & $\begin{array}{c}\text { Synonymous variant } \\
\text { (p. Val53=) }\end{array}$ \\
\hline
\end{tabular}

All information was taken from the NCBI database (http://www.ncbi.nlm.nih.gov/).

in Iran.(4) This variant increased the risk of getting nonsmall cell lung cancer incidence among the Han Chinese population $(\mathrm{OR}=2.50 ; 95 \% \mathrm{CI}=1.04-5.97) .(5)$ This variant also had a high linkage disequilibrium with the CHRNA5 rs16969968 variant, a pathogenic variant that changes amino acid from aspartic acid to asparagine. Mutant allele C from the CHRNA3 rs8040868 is known to be associated with a decreased expression of the CHRNA5 gene in lung tissue.(6)

Over the last years, genome-wide association studies and other candidate gene analyses have been done to map SNV and its association with various physiological and clinical traits in humans. To validate the association of SNV to a disease, a large number of subjects must be studied, thus making scientists in need of a feasible genotyping method without expensive tools or reagents.(7) The advanced laboratory uses DNA microarray genotyping/DNA biochip for mass genotyping analysis. This advancement is difficult to operate in general molecular laboratories commonly operated in developing countries such as Indonesia, due to expensive infrastructure and consumables. An example of genotyping methods that utilize common qualitative polymerase chain reaction (PCR) machines with more robust, more efficient, and yet valid is Tetra-primer Amplification Refractory Mutation Systems PCR (Tetraprimer ARMS PCR). This method uses two different sets of primers, outer and inner primer pairs. The outer primers were used to amplify the target gene sequence, while the inner primers were used to identify base variations that occur in the gene sequence.(8) Variations of alleles will be on different band sizes which can be differentiated by further visualization by using UV after gel electrophoresis. PCR efficiency and gene specificity will be ensured by outer primer pairs while allele specificity will be ensured by inner primer pairs.(2)

Tetra-primer ARMS PCR is an accurate, easy, practical, and inexpensive genotyping method. The required tools and materials are the same as conventional PCR. Further, the result of Tetra-primer ARMS PCR can be detected by gel electrophoresis to determine the genotype of the samples tested.(8) Besides, Tetra-primer ARMS PCR has advantages to detect variants present in low percentage in specific disease due to the 'mutant enrichment' method. Four low penetrance variants in breast cancer prediction had been successfully genotyped using this method. $(9,10)$ Therefore, this method can be used to detect somatic mutation (i.e., tumor tissue, leukemia, etc.), not just germline variants from blood.(10)

This manuscript describes the strategy used to develop Tetra-primer ARMS PCR-based genotyping for rs8040868 $(\mathrm{T} / \mathrm{C})$ variation. Steps used within this report can also be used as a template to develop Tetra-primer ARMS PCRbased genotype detection.

\section{Methods}

The experiment was performed under the approval of the ethics committee of the Faculty of Medicine, Public Health, and Nursing, Universitas Gadjah Mada (No. KE/0922/ $\mathrm{EC} / 2019)$.

\section{Samples}

We used a total of 10 DNA samples isolated from the peripheral blood of volunteers. Two samples were used in the Tetra-primer ARMS PCR optimization step, while 8 were used in the validation step.

\section{DNA Extraction}

Control genomic DNA used for this study was obtained from the buffy coat of peripheral blood of adult volunteers $(\mathrm{n}=2)$, coded as $\mathrm{K} 1$ and K2. DNA extraction was done by using QIAmp DNA Mini Kit No. 51304 (Qiagen, Germantown, MD, USA). The procedures were carried out according to the kit. DNA quantity DNA was examined by using spectrophotometer NanoDrop (Thermo Fisher Scientific, Waltham, MA, USA) and ran in $2 \%$ gel agarose electrophoresis (GeneDireX, Taoyuan, Taiwan) to check its quality.

\section{Primer Design}

The minor allele frequency (MAF) of rs8040868 was checked in several genome projects based on its closure to the Indonesian population (Table 2). This step was done to make sure that the variant can be found in our tested samples. The DNA sequence of CHRNA3 rs8040868 was 
Table 2. MAF of CHRNA3 rs8040868.

\begin{tabular}{ccccc}
\hline \multirow{2}{*}{ Gene Variant } & \multicolumn{4}{c}{ Minor Allele Frequency (MAF) } \\
\cline { 2 - 5 } & $\begin{array}{c}\text { Malay } \\
\text { Population* }\end{array}$ & $\begin{array}{c}\text { Chinese } \\
\text { Population* }\end{array}$ & $\begin{array}{c}\text { Vietnam } \\
\text { Population** }\end{array}$ & $\begin{array}{c}\text { East Asian } \\
\text { Population*** }\end{array}$ \\
\hline $\begin{array}{c}C H R N A 3 \\
\text { rs8040868 }\end{array}$ & 0.511 & 0.413 & 0.344 & 0.354 \\
\hline
\end{tabular}

The data was taken from: *The Singapore Genome Variation Project (https://blog.nus.edu.sg/ sshsphphg/singapore-genome-variation/); **A Vietnamese Human Genetic Variation database (https://genomes.vn/); and ***The 1000 GENOME phase 3 project (https://www.ncbi.nlm.nih.gov/ snp/rs8040868\#frequency_tab).

identified from an accessible NCBI database (http://www. ncbi.nlm.nih.gov/). Two specific sets of outer and inner PCR primers (later written as "primers") were designed using web-based software Primer1 (http://primer1.soton. ac.uk/public_html/primer1.html).(8) Primer's specificity to detect CHRNA3 gene was tested using NCBI BLAST program (http://www.ncbi.nlm.nih.gov/blast). The primers used for Tetra-primer ARMS PCR for detection CHRNA3 rs8040868 were provided in Table 3. DNA sequence used to design primers, the schematic illustration of the Tetraprimer ARMS PCR for CHRNA3 rs8040868, and its expected PCR product were started in Figure 1. Further, gene fragments of CHRNA3 from two DNA samples (K1 and K2) were amplified using the designed outer primers. Results were run in $2 \%$ agarose electrophoresis to observe the target-size DNA fragment.

\section{Confirmation of Genotype}

The genotype of the PCR product with the expected DNA size (Figure 2) was further confirmed by Sanger DNA sequencing (Figure 3). PCR product and the outer primer in a total volume of $30 \mu \mathrm{L}$, respectively, were sent to $1^{\text {st }}$ Base Sequencing Laboratories (Selangor, Malaysia) for sample processing. The result was analyzed using free website software Poly Peak Parser (http://yosttools.genetics.utah. edu/PolyPeakParser/).

\section{Optimization Steps of Tetra-primer ARMS PCR}

Optimization of Tetra-primer ARMS PCR was done in three steps, which include: determining the ratio of outer and inner primers; searching for the optimum annealing cycle and temperature; and using the correct concentration of the PCR reagents to minimize nonspecific bands. The total volume of PCR reaction was $20 \mu \mathrm{L}$; containing $10 \mu \mathrm{L}$ GoTaq ${ }^{\circledR}$ Green Master Mix (2X Green GoTaq ${ }^{\circledR}$ Reaction Buffer ( $\mathrm{pH} 8.5$ ), $400 \mu \mathrm{M}$ dATP, $400 \mu \mathrm{M}$ dGTP, $400 \mu \mathrm{M}$ dCTP, $400 \mu \mathrm{M}$ dTTP, and $3 \mathrm{mM} \mathrm{MgCl}$ (Promega Corporation, Madison, WI, USA), an optimized ratio of outer and inner primers (each primer has working stock concentration $10 \mathrm{nM} / \mu \mathrm{L}$ ), and genomic DNA (50-200 ng/ $\mu \mathrm{L})$. DNA amplification was done by using Thermocycler PCR ProFlex Applied Biosystem (Life Technologies Holdings Pte, Ltd, Singapore).

The optimization of Tetra-primer ARMS PCR was performed by applying different ratios of outer and inner primer concentration between $1: 1,1: 2,1: 3$, and 1:4. The annealing temperature was determined by lowering the average melting temperature by $5^{\circ} \mathrm{C}$ and gradually increased

Table 3. Primers used in Tetra-primer ARMS PCR genotyping.

\begin{tabular}{llcc}
\hline \multicolumn{1}{c}{ Variant } & \multicolumn{1}{c}{ Primary Sequence } & Product (bp) & Tm $\left({ }^{\mathbf{0}} \mathbf{C}\right)$ \\
\hline $\begin{array}{l}\text { CHRNA3 } \\
\text { rs8040868 }\end{array}$ & $\begin{array}{l}\text { Forward outer primer }\left(5^{\prime}-3^{\prime}\right) \text { : } \\
\text { AGACTGGCCTGAAAGTCTAGGGTTCCAC }\end{array}$ & 353 & 70.9 \\
& $\begin{array}{l}\text { Reverse outer primer }\left(5^{\prime}-3^{\prime}\right) \text { : } \\
\text { GACTAATTCTGGGAAAGGCTCCTCCAGA }\end{array}$ & 353 & 69.9 \\
& $\begin{array}{l}\text { Forward inner primer (Allele C): } \\
\text { AAGATTACAATGAGATCATCCGGCCTTTG }\end{array}$ & 165 & 66.9 \\
& $\begin{array}{l}\text { Reverse inner primer (Allele T): } \\
\text { GATGATGACTGGGTCAGACACGTTGTCT }\end{array}$ & 245 & 69.9 \\
\hline
\end{tabular}

Primers were designed by using the Primerl program (http://primer1.soton.ac.uk/public_html/ primerl.html). 
A. 1741 GGTAAAGACA CAGGTTCAGA GAGGTTAAGC CACTTGCCTA AGCTCACACA GCTTACAAGT 1801 GATTTGTCAG GATTTGCACC AGATCTGTCC AACTCCAGAG CCCAGGCTTG CAACCACTGT 1861 GCTTCTCACT GAATGCGTGT GGCCAGGTAG AATCCTGCCC CTCTTGGGCC TCAGTTTCCC 1921 ATTTTGTAAC CCACTGGGTT AGACTGGCCT GAAAGTCTAG GGTTCCACAG AATCCCCCCA 1981 CAGGTGGAGG GGATGCTGTA GATGGGTGAT GTTTCTGCTG GGCTGGGTGG GGGAGGTTAA 2041 GTAACGATTT CCCCAGGGAC TGACAGGGCT GCTTCCCACA GTGGCCAGGG CCTCAGAGGC 2101 TGAGCACCGT CTATTTGAGC GGCTGITTGA AGATTACAAT GAGATCATCC GGCCTGT[A/G]AGC 2161 CAACGTGTCT GACCCAGTCA TCATCCATTT CGAGGTGTCC ATGTCTCAGC TGGTGAAGGT 2221 GGTGAGTGCT GGAAGCCACG AGCCGTGGCC ATGGGGACCG GGGCTTCTGG AGGAGCCTTT 2281 CCCAGAATTA GTCTTGTTTT GTAATTCTCC TGTCAACTTT AATTCCTCTT TCTAGGATGA

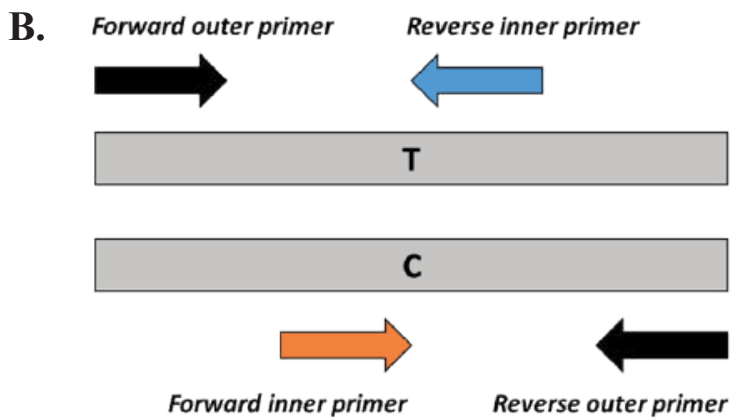

C.

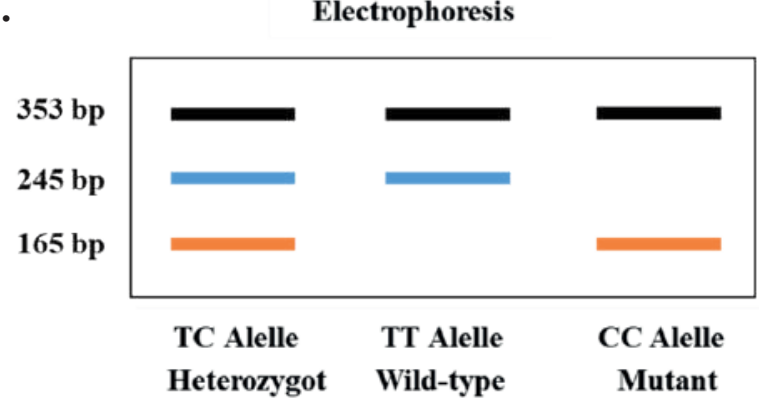

Figure 1. Tetra-primer ARMS PCR for CHRNA3 rs8040868. A: DNA sequence used to design primers for CHRNA3 rs8040868. The green-colored sequence indicates the specific exon where the variants present. The yellow-colored sequence indicates the changed codon. B: Schematic illustrations of the Tetra-primer ARMS PCR assay for genotyping. T and C indicate the allele changes between thymine to cytosine. C: Expected product from Tetra-primer ARMS PCR after ran on 2\% agarose gel electrophoresis.

by $1^{\circ} \mathrm{C}$, as advised by the PCR kit. Gradients of annealing temperature were at $64.4^{\circ} \mathrm{C}, 65.4^{\circ} \mathrm{C}, 66.4^{\circ} \mathrm{C}$, and $67.4^{\circ} \mathrm{C}$. The annealing cycle was done in 35 or 40 cycles.

The optimum outer and inner primers ratio was 1:3 and the optimum PCR conditions were stated in Table 4.

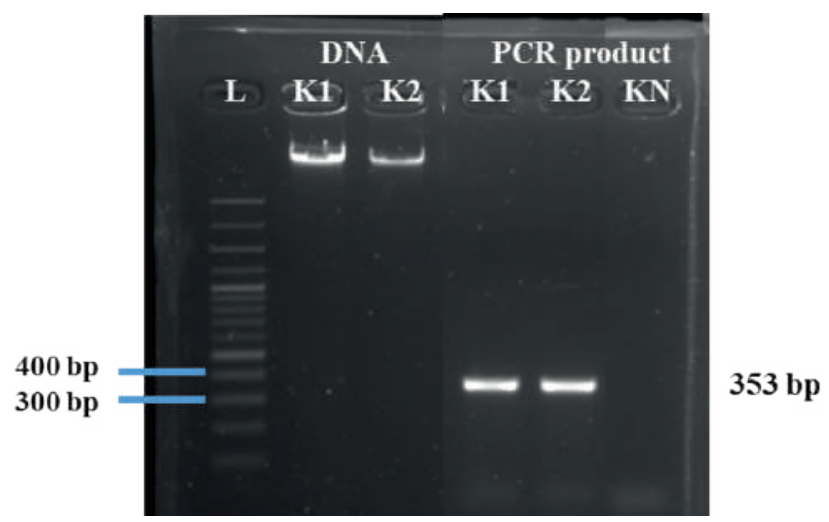

Figure 2. DNA quality of K1 and K2 samples, and conventional PCR product with outer primers under $2 \%$ agarose gel electrophoresis. Single K1 and K2 bands showed good and intact genomic DNA. The use of outer primers produced $353 \mathrm{bp}$ of DNA band, as expected. (L: DNA ladder; K1: sample 1; K2: sample 2: $\mathrm{KN}$ : negative control).
The simplified step based on the optimization result can be seen in Figure 4. For visualization, PCR products were run in $2 \%$ agarose gel electrophoresis against FlouroVue DNA marker 50 and $100 \mathrm{bp}$ difference (Smobio Technology, Hsinchu, Taiwan). The images were visualized under UV transillumination in GelDoc (Syngene, Cambridge, United Kingdom).

\section{Results}

Table 3 shows the MAF of the reference population of the Malay, Chinese, Vietnamese, and East Asian population. We concluded it is possible to detect the CHRNA3 rs8040868, as the MAF was spanned from 0.51-0.344.

Further, a set of outer primers were designed based on the CHRNA3 DNA sequence that includes the rs 8040868 locus. Following PCR using the outer primers, the product obtained confirmed that the outer primer set has successfully amplified targeted DNA fragments of CHRNA3 at the correct size, $353 \mathrm{bp}$. The same PCR products were analyzed by the Sanger sequencing method, confirming the sequence 
Forward sequence

A.

\section{Reverse sequence}

AC G T T G GCT TACAG G C C G GAT GA' AC G T T G GC ACAGG C C G GAT GA'

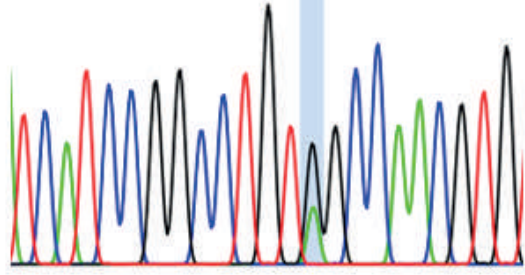

B.
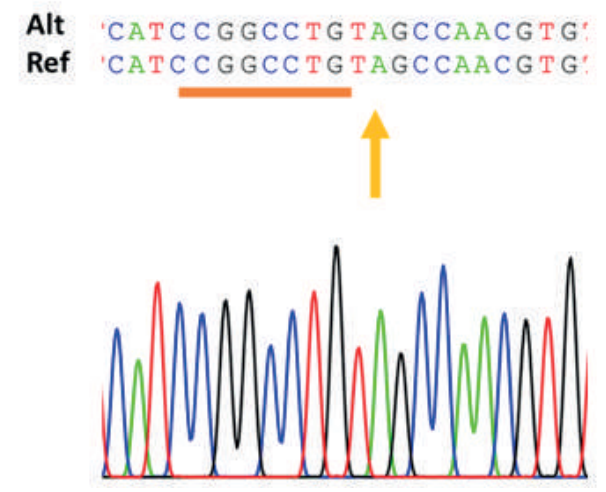

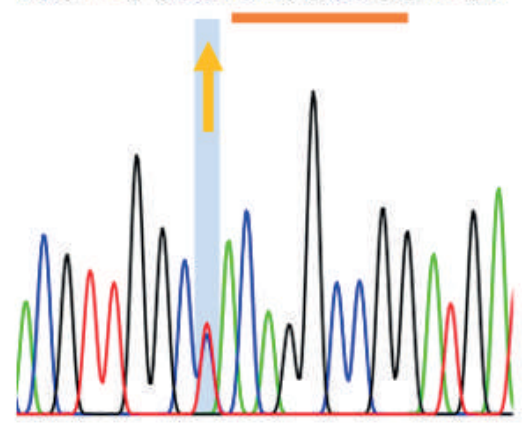

ACG T T G GC T ACAGGCCGG ATGA: ACG T T GCT ACAGGCCGG ATGA:

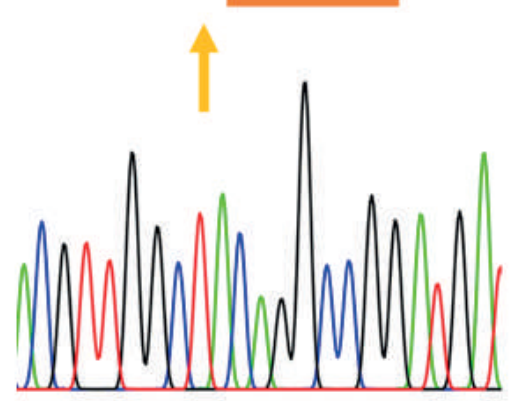

Forward sequence

: CCGGCCTGT A/G

Reverse sequence

: GGCCGGACA T/C

Figure 3. Sanger sequencing result of K1 (A) and K2 (B) samples. The red line shows the place where the "keywords" were found. The yellow-colored arrow shows that the $\mathrm{K} 1$ has $\mathrm{G}$ codon in forward sequence and $\mathrm{C}$ codon in reverse sequence; the blue line indicates that the changes are heterozygous, thus the $\mathrm{K} 1$ sample has $\mathrm{CT}$ allele. The $\mathrm{K} 2$ has A codon in forward sequence and $\mathrm{T}$ codon in reverse sequence, making the sample have the TT allele (wild-type). (Alt: alternative allele, means the sequence that is analyzed; Ref: Reference allele).

of CHRNA3 fragment and the genotype of $\mathrm{K} 1$ (CT allele; heterozygous mutant) and K2 (TT allele; homozygous wild type).

The melting temperature (Tm) means of primers that we used was $69.4^{\circ} \mathrm{C}$. We tried to optimize for the best

Table 4. Reagent mix for Tetra-primer ARMS PCR CHRNA3 rs8040868.

\begin{tabular}{lcc}
\hline \multicolumn{1}{c}{ Reagent } & $\begin{array}{c}\text { Working } \\
\text { Concentration }\end{array}$ & Volume \\
\hline GoTaq ${ }^{\circledR}$ Green Master Mix & & $10 \mu \mathrm{L}$ \\
Nuclease Free Water & $10 \mathrm{nM}$ & $7.4 \mu \mathrm{L}$ \\
Forward outer primer & $10 \mathrm{nM}$ & $0.2 \mu \mathrm{L}$ \\
Reverse outer primer & $10 \mathrm{nM}$ & $0.6 \mu \mathrm{L}$ \\
Forward inner primer & $10 \mathrm{nM}$ & $0.6 \mu \mathrm{L}$ \\
Reverse inner primer & $50-200 \mathrm{ng} / \mu \mathrm{L}$ & $1 \mu \mathrm{L}$ \\
DNA & & $\mathbf{2 0} \boldsymbol{\mu L}$ \\
\hline Total volume & &
\end{tabular}

annealing temperature from $64.4^{\circ} \mathrm{C}$ and gradually increased $1^{\circ} \mathrm{C}$ until $67.4^{\circ} \mathrm{C}$. In the same PCR reaction, we applied four different ratios of outer and inner primer $(1: 1,1: 2,1: 3$, and 1:4). We identified that PCR results in 1:2 and 1:3 primers ratio with $64.4^{\circ} \mathrm{C}$ yielded the best product. Subsequently, due to the thin band, we added the annealing cycles from $35 \mathrm{X}$ to $40 \mathrm{X}$. Based on the optimization process, the final ratio for outer and inner primer concentration was 1:3, optimum annealing temperature was $64.4^{\circ} \mathrm{C}$, and 40 cycles were used.

Detailed mixed reagents for Tetra-primer ARMS PCR and the PCR program were listed in Table 4 and Table 5. Optimized Tetra-primer ARMS PCR product ran in 2\% gel electrophoresis and showed $165 \mathrm{bp}, 245 \mathrm{bp}$, and 353 DNA bands for K1 and 245 bp and 353 bp DNA bands for K2 (Figure 4). This result confirmed that the genetic variation of control samples was heterozygous mutant (K1; CT allele) and homozygous wild-type (K2; TT allele) respectively; consistent with the sequencing results. 

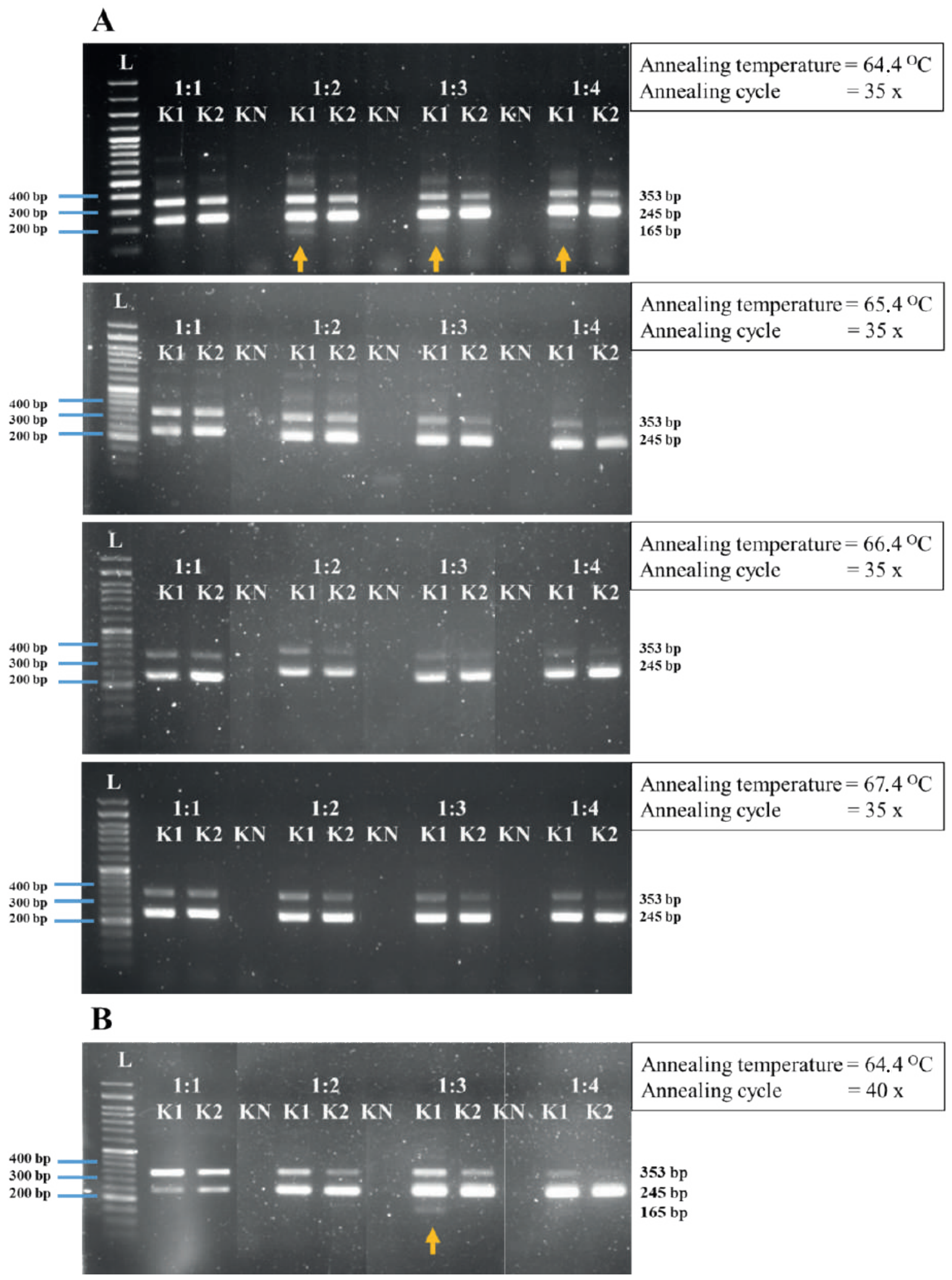

Figure 4. The optimization process of Tetra-primer ARMS PCR to detect $C H R N A 3$ rs8040868. PCR products run in $2 \%$ of agarose gel. A: PCR with a variety of outer and inner primer ratios of $1: 2,1: 3$, and $1: 4$ in $64.4^{\circ} \mathrm{C}, 65.4^{\circ} \mathrm{C}, 66.4^{\circ} \mathrm{C}$, and $67.4^{\circ} \mathrm{C}$ annealing temperatures $($ see the label in each picture), all done in $35 \mathrm{x}$ PCR cycles. Results showed an annealing temperature of $64.4^{\circ} \mathrm{C}$ as the optimum PCR condition, which showed the heterozygous band in $\mathrm{K} 1$ (yellow arrow). B: To get a clearer band, an additional cycle was added. Optimization with 1:3 outer and inner primer ratio by using $64.4^{\circ} \mathrm{C}$ annealing temperatures with $40 \mathrm{x}$ annealing cycle to increases specificity of the PCR process, shows the best result (L: ladder; K1: sample 1; K2: sample 2: KN: negative control). 
Table 5. Tetra-primer ARMS PCR CHRNA3 rs8040868 program.

\begin{tabular}{lccc}
\hline \multicolumn{1}{c}{ Reagent } & Times & Temperature & Cycle number \\
\hline Initial denaturation & 2 minutes & $95^{\circ} \mathrm{C}$ & 1 cycle \\
Denaturation & 30 seconds & $95^{\circ} \mathrm{C}$ & \\
Annealing & 30 seconds & $64.4^{\circ} \mathrm{C}$ & 40 cycles \\
Elongation & 1 minute & $72^{\circ} \mathrm{C}$ & \\
Termination & 5 minutes & $72^{\circ} \mathrm{C}$ & 1 cycle \\
Cooldown & $\sim$ & $4^{\circ} \mathrm{C}$ & \\
\hline
\end{tabular}

\section{Discussion}

$\mathrm{SNV}$ is a molecular marker which was widely used because of their ubiquitous distributions throughout the genome. The increasing number of SNV markers has led to increasing demand for numerous cost-effective genotyping platforms. (11) Genotyping to detect genetic susceptibility can be done by several methods, including sequencing, genotyping array, Restriction Fragment Length Polymorphism (RFLP), and RT-PCR with probes.(7) Several studies have reported the use of different genotyping methods to detect SNV. (12-15) Despite that, each method has different advantages and disadvantage to consider. Sequencing and genotyping array are a high-throughput genotyping technique but they need expensive machineries and reagents. Using qPCR will equally requires expensive reagents; the later technology the more expensive the technology. PCR-RFLP is more common to be used in less sophisticated research laboratory, as it needs only conventional PCR machine and generic PCR reagents, but it is limited as its analysis will be only possible if the SNV creates a restriction enzyme site.(7) Thus, this is a two-steps process prior to detection by using agarose gel electrophoresis, can not be used for mass analysis, and often not reproducible.

The application of Tetra-primer ARMS PCR to identify genetic variation has been widely reported. Tetra-primer ARMS PCR has been known to be the combination of Tetraprimer PCR and ARMS PCR, by using conventional PCR machine and generic PCR reagents. Tetra-primer ARMS PCR has a higher sensitivity and accuracy in comparison to ARMS PCR, specifically in distinguishing normal and heterozygotes allele.(16) Tetra-primer ARMS PCR is a reliable method to analyze point mutations. It delivers fast results and enables the identification of specific genotypes in a single PCR step. It is also less time-consuming, once the melting temperature is optimized, and more affordable than genotyping using restriction enzyme.(17) This method can detect insertion and deletions, such as variation of rs4343 $\mathrm{A}>\mathrm{G}$ and $\mathrm{rs} 4340$ insertions/deletions in artery coronary disease study.(18) Also, this method can be used to detect variations in miRNA genes, such as miR-146a rs2910164 $\mathrm{C}>\mathrm{G}$ gene in breast cancer study.(19) Not only in humans, but Tetra-primer ARMS PCR also has been reported to detect g.4140 A $>$ G polymorphism in the SIRT2 gene of cattle.(20)

This study follows our previous optimization strategy to detect variation CYP2E1 gene.(1) First, we design the outer and inner primers using Primer 1.(21) Primer design is a critical step to ensure the success of the development of Tetra-primer ARMS PCR.(2) A successful primer set depends on the primer Tm, GC content percentage, and the selection of mismatch bases.(21) The interaction between the inner and outer primers may also affect the specificity of the reaction.(2)

Designing outer primer is important to amplify selected DNA target, that further becoming positive control once the genotype confirmation is done. Genotype confirmation by using sequencing is needed to validate whether the PCR product indeed amplifies the correct DNA sequence. Choosing the correct inner primer pairs is the key element in the development of Tetra-primer ARMS PCR, as this determines the genotype of DNA sample variant. To design the inner primers, the free software Primer1 equips the inner primer with the mismatch. $(1,8,16,21) \mathrm{We}$ designed the inner primer where each has 2 mismatches, at the 3' end and position -2 from the 3' end. The latter mismatch is supposed to increase the specificity of allele detection, as consequently DNA polymerase will only able to elongate when its $3^{\prime}$ end is complemented perfectly to the template.(7) It is also important to choose a set of inner primers which has a target band with a minimum difference of $50 \mathrm{bp}$, so it can be separately differentiated using $2 \%$ gel electrophoresis. 
The second step was finding the optimum concentration ratio of the outer and inner primer.(1) The use of more than one pair of primers poses a challenge. Having two sets of primers will increase the chances of getting non-specific products that can be seen when they were visualized by showing multiple DNA bands. This result happens because dimers may be formed between the primers, and many unwanted reactions may increase during the PCR cycle.(7)

To overcome this, having the most suitable ratio between the outer and inner primer is a must. Previous studies reported that the ratios between the outer and inner primer differed depending on which codon was amplified. (22) Some studies reported different ratios one to another, but they always use less concentration of outer primer than inner primer. $(8,23,24)$ Reducing the concentrations of the outer primer will enhance the amplification of the allelespecific product. Additionally, we also found that lowering the outer primers concentration truly gives the best result even though it may give a lesser clear DNA band under UV transillumination, similar to the previous finding.(8)

We were also searching for the optimum annealing temperature simultaneously with finding the best primer ratio. Both factors were solved by using a gradient PCR system which allows different annealing temperatures in one PCR process. For the optimum annealing temperature, $5^{\circ} \mathrm{C}$ lower than average melting temperature is suggested to show the most stable product.(8) This suggestion was confirmed in our study. However, other studies also showed that the optimum annealing temperature was closer to the average melting temperature.(1,7) We concluded that different variants may give different results; so, optimization still requires a variety of temperatures. It is also important to try adding PCR cycles if the expected DNA band cannot be seen clearly under the UV transilluminator.

This study posed a limitation, as we could only detect 2 of 3 expected variants, i.e., homozygous wild type and heterozygous mutant, despite our attempt to use DNA samples from 10 different subjects (part of data not shown). Additionally, the use of this method by using different DNA sources needs to be validated.

\section{Conclusion}

Tetra-primer ARMS PCR was successfully employed to accurately determine the genotype of the rs 8040868 variant in the CHRNA3 gene. This method was simple, affordable, and can be easily adapted to detect other genetic variants.

\section{Acknowledgements}

This work was supported by "Hibah Rekognisi Tugas Akhir (RTA)", Universitas Gadjah Mada, Indonesia year 2020 (PI: Fachiroh J). The authors would also thank the donors and technicians who participated in this research.

\section{Authors Contribution}

JF, ALD, DK designed the study. ALD carried out the laboratory work. ALD, DK, JF analyzed the data. ALD and JF wrote the manuscript. All authors read and approved the final version of the manuscript.

\section{References}

1. Suhda S, Paramita DK, Fachiroh J. Tetra primer ARMS PCR optimization to detect single nucleotide polymorphisms of the CYP2E1 gene. Asian Pacific J Cancer Prev. 2016; 17: 3065-9.

2. Zabala AS, Gomez MEV, Alvarez MF, Siewert S. Tetra primer ARMS PCR optimization to detect single nucleotide polymorphism of the KLF14 gene. OALib Journal. 2017; 4: e4145. doi: 10.4236/ oalib.1104145.

3. Lassi G, Taylor AE, Timpson NJ, Kenny PJ, Mather RJ, Eisen T, et al. The CHRNA5-A3-B4 gene cluster and smoking: from discovery to therapeutics. Trends Neurosci. 2016; 39: 851-61.

4. Mehrabi N, Moshtaghioun SM, Neamatzadeh H. Novel mutations of the CHRNA3 gene in non-small cell lung cancer in an Iranian population. Asian Pacific J Cancer Prev. 2017; 18: 253-5.

5. Sun Y, Li J, Zheng C, Zhou B. Study on polymorphisms in CHRNA5/ CHRNA3/CHRNB4 gene cluster and the associated with the risk of non-small cell lung cancer. Oncotarget. 2017; 9(2): 2435-44.

6. Mattson H, Soderhall C, Einarsdottir E, Lamontagne M, Gudmundsson $\mathrm{S}$, Backman $\mathrm{H}$, et al. Targeted high-throughput sequencing of candidate genes for chronic obstructive pulmonary disease. BMC Pulm Med. 2016; 16: 146. doi:10.1186/s12890-016-0309-y.

7. Medrano RFV, de Oliveira CA. Guidelines for the tetra primer ARMS-PCR technique development. Mol Biotechnol. 2014; 56: 599-608.

8. Ye S. An efficient procedure for genotyping single nucleotide polymorphisms. Nucleic Acids Res. 2001; 29: 88e-88.

9. Zhang C, Liu Y, Ring BZ, Nie K, Yang M, Wang M, et al. A novel multiplex tetra-primer ARMS-PCR for the simultaneous genotyping of six single nucleotide polymorphisms associated with female cancers. PLoS One. 2013; 8: e62126.

10. Milbury CA, Li J, Makrigiorgos GM. PCR-based methods for the enrichment of minority alleles and mutations. Clin Chem. 2009; 55: $632-40$.

11. Broccanello C, Chiodi C, Funk A, McGrath JM, Panella L, Stevanato P. Comparison of three PCR-based assays for SNP genotyping in plants. Plant Methods. 2018; 14: 28. doi:10.1186/ s13007-018-0295-6.

12. Sahiratmadja E, Penggoam S, Maskoen AM, Pramono AA, Aryani D, Rahayu NS, et al. Distribution of rs1801279 and rs1799930 
polymorphisms in NAT2 gene among population in Kupang, Nusa Tenggara Timur, Indonesia. Indones Biomed J. 2018; 10: 56-61.

13. Neela PK, Gosla SR, Husain A, Mohan V, Thumoju S, Rajeshwari R. Analysis of single nucleotide polymorphisms on locus 13q33.1-34 in multigenerational families of cleft lip palate using MassArray. Indones Biomed J. 2021; 13: 27-33.

14. Ugrasena IDG, Notopuro H, Sudarmo SM, Sudiana K, Gatot D, et al. MTHFR C677T and TS 5'-UTR 3R/3R gene polymorphism in methotrexate-resistant childhood acute lymphoblastic leukemia. Indones Biomed J. 2020; 12: 177-182.

15. Tursinawati Y, Hakim RF, Rohmani A, Kartikadewi A, Sandra F. CAPN10 SNP-19 is associated with susceptibility of type 2 diabetes mellitus: A Javanese case-control study. Indones Biomed J. 2020; 12: 109-114.

16. Honardoost MA, Tabatabaeian H, Akbari M, Salehi M. Investigation of sensitivity, specificity and accuracy of Tetra primer ARMS PCR method in comparison with conventional ARMS PCR, based on sequencing technique outcomes in IVS-II-I genotyping of beta thalassemia patients. Gene. 2014; 549: 1-6. doi: 10.1016/j. gene.2014.05.071

17. Linjawi S, Al-Gaithy Z, Sindi S, Hamdi N, Linjawi A, Alrofidi A. Tetra-primer ARMS PCR as an efficient alternative for SNPs detection in molecular diagnostic: a comparison study. EJPMR. 2019; 6: 91-6.
18. Heidari MM, Hadadzadeh M, Fallahzadeh H. Development of One-step tetra-primer ARMS-PCR for simultaneous detection of the angiotensin converting enzyme (ACE) I/D and rs4343 gene polymorphisms and the correlation with CAD patients. Avicenna J Med Biotechnol. 2019; 11: 118-23.

19. Afzal M, Rahim A, Naveed AK, Ahmed S, Kiyani MM. Development of cost-effective Tetra-primer Amplification Refractory Mutation System (T-ARMS) PCR for the detection of miR-146a gene rs2910164 C/G polymorphism in breast cancer. Biochem Mol Biol J. 2018; 4: 1-4. doi:10.21767/2471-8084.100050.

20. Li M, Sun X, Jiang J, Sun Y, Lan X, Lei C, et al. Tetra-primer ARMSPCR is an efficient SNP genotyping method: An example from SIRT2. Anal Methods. 2014; 6: 1835-40.

21. Collins A, Ke X. Primer1: primer design web service for tetra-primer ARMS-PCR. Open Bioinformatic J. 2012; 6: 55-8.

22. Hou Y, Luo Q, Chen C, Zhou M. Application of tetra primer ARMSPCR approach for detection of Fusarium graminearum genotypes with resistance to carbendazim. Autralasian Plant Pathol. 2013; 42: 73-8.

23. Bu Y, Gu ZL, Zhang XD, Zhou GH. A rapid single-tube SNP typing based on tetra-primer PCR amplification. Chin J Biochem Mol Biol. 2004; 20: 252-6.

24. Guan F, Yang LG, An JT, Liu SR, Shi GQ. Development of a rapid mismatch PCR method using tetra-primer ARMS for detection of BMPR-IB gene mutation in sheep. Hereditas. 2005; 27: 579-83. 